\title{
Antimicrobial Resistance of Escherichia coli and Salmonella isolated from Retail Broiler Chicken Carcasses in Zambia
}

\author{
Elizabeth Muligisa-Muonga*1, Geoffrey Mainda ${ }^{2}$, Mercy Mukuma ${ }^{3}$, Geoffrey Kwenda ${ }^{4}$, Bernard Hang'ombe ${ }^{5}$, \\ Bumbangi Nsoni Flavien ${ }^{6}$, Nelson Phiri ${ }^{1}, M_{w a b a ~ M w a n s a}{ }^{7}$, Musso Munyeme ${ }^{8}$, John Bwalya Muma ${ }^{8}$ \\ ${ }^{1}$ Department of Environmental Health, School of Medicine and Health Sciences, Eden University, Lusaka, Zambia \\ ${ }^{2}$ Department of Veterinary Services - Public Health Unit, Ministry of Fisheries and Livestock, Lusaka, Zambia \\ ${ }^{3}$ Department of Food Science and Nutrition, School of Agricultural Sciences, University of Zambia, Lusaka, Zambia \\ ${ }^{4}$ Department of Biomedical Sciences, School of Health Sciences, University of Zambia, Lusaka, Zambia \\ ${ }^{5}$ Department of Paraclinical Studies, School of Veterinary Medicine, University of Zambia, Lusaka, Zambia \\ ${ }^{6}$ Department of Disease Control and Prevention, School of Medicine and Health Sciences, Eden University, Lusaka, Zambia \\ ${ }^{7}$ Department of Basic Sciences, School of Medicine, Copperbelt University, Ndola, Zambia \\ ${ }^{8}$ Department of Disease Control, School of Veterinary Medicine, University of Zambia, Lusaka, Zambia
}

Received: February 4, 2021

DOI: $10.5430 /$ jer.v6n1p35
Accepted: April 8, 2021

URL: https://doi.org/10.5430/jer.v6n1p35

\begin{abstract}
Antimicrobial resistance (AMR) of foodborne pathogens is of public health concern, especially in developing countries such as Zambia. This study was undertaken to determine the antimicrobial resistance profiles of Escherichia coli (E. coli) and Salmonella isolated from retail broiler chicken carcasses purchased from open markets and supermarkets in Zambia. A total of 189 E. coli and five Salmonella were isolated. Identification and confirmation of the isolates were done using Analytical Profile Index (API 20E) (Biomerieux ${ }^{\circledR}$ ) and 16S rRNA sequencing. Antimicrobial susceptibility tests (AST) were performed using the Kirby Bauer disk diffusion technique using a panel of 9 antibiotics. WHONET 2018 software was used to analyze AST results. The E. coli isolates were mostly resistant to tetracycline (79.4\%), ampicillin (51.9\%), and trimethoprim/sulfamethoxazole (49.7\%). Two of the five Salmonella isolates were resistant to at least one antibiotic. This study has demonstrated the presence of AMR E. coli and Salmonella on retail broiler chicken carcasses from open markets and supermarkets, which is of public health concern.
\end{abstract}

Key Words: Antimicrobial resistance, E. coli, Salmonella, Poultry, Zambia

\section{INTRODUCTION}

Poultry meat forms an integral part of the diet, especially in developing countries. It is popular because it is a cheaper source of protein and easy to produce compared to other meat products. ${ }^{[1]}$ However, the high demand for poultry meat puts a strain on producers, who have to meet the ever-growing demand and realize profits in a competitive market environ- ment. ${ }^{[2]}$ One of the strategies producers often resort to is the use of antibiotics to prevent and treat diseases of poultry to optimize growth. ${ }^{[3]}$

Antibiotics are also used for growth promotion. However, if they are misused, they can lead to the development of resistance in bacteria found in chickens. In the absence of a national surveillance system on the use of antibiotics, it is

\footnotetext{
*Correspondence: Elizabeth Muligisa-Muonga; Email: elizabethmuligisa@ gmail.com; Address: School of Medicine and Health Sciences, Eden University, P. O BOX 37727, Lusaka, Zambia.
} 
difficult to know whether they are being used appropriately. ${ }^{[4]}$

In monitoring the development of antimicrobial resistance (AMR) in bacteria, Escherichia coli (E. coli) is commonly used because it is part of the gut microbiota and is a reservoir for AMR genes. ${ }^{[5,6]}$ AMR occurs when bacteria, viruses, fungi and parasites no longer respond to the antimicrobials designed to kill them. ${ }^{[7]}$ Despite E. coli being an innocuous resident of the digestive system, it can also be pathogenic and cause severe intestinal and extra-intestinal diseases. ${ }^{[8]}$ Recent studies showed that $E$. coli is involved in 48 million reported cases of foodborne illness worldwide. ${ }^{[9]}$ Furthermore, among the foodborne bacterial enteropathogens, $E$. coli, Salmonella sp. and Campylobacter sp. are responsible for most diarrhoeal diseases that affect millions of people annually, sometimes with fatal outcomes. ${ }^{[10]}$

Besides, non-typhoidal Salmonella species are responsible for causing gastroenteritis and bacteremia, which can eventually lead to secondary infection, especially in immunecompromised individuals such as patients with malignancy, human immunodeficiency virus, diabetes, and those receiving medication for anti-inflammatory diseases. ${ }^{[11]}$

E. coli and Salmonella sp. infections can be treated using relevant antibiotics. However, there is accumulating evidence of the consequences of AMR, including the reduction in the efficacy of treatment with first-line drugs and limited choices after microbiological diagnosis. ${ }^{[12,13]}$

In Zambia, recent findings showed that Salmonella sp. and E. coli (18\% and $25.5 \%$, respectively) were among the most detected organisms causing bacterial diarrhoeal disease in children between the ages of 0-59 months at the University Teaching Hospital. ${ }^{[14]}$ In this age category, most diarrhoeal cases are more likely to be caused by foodborne pathogens, especially in developing countries where food safety prob-

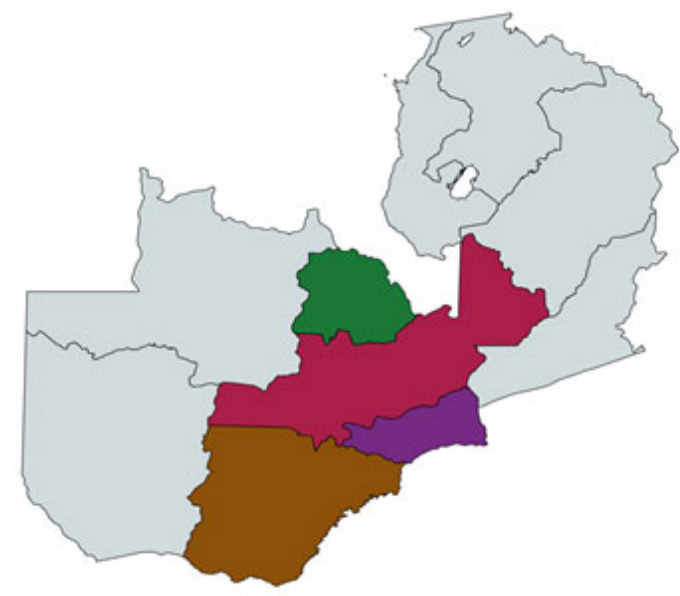

lems and poor hygiene and sanitation are recurrent. ${ }^{[15,16]}$

Further, several reports from different countries elucidate a growing concern of AMR in foodborne pathogens, negatively impacting public health. ${ }^{[12,13,17]}$ However, there is a paucity of information on AMR occurrence on foodborne pathogens in Zambia. Furthermore, in a growing industry of broiler chicken production and consumption in Zambia, the misuse of antimicrobials for growth promotion, prevention and treatment of diseases could contribute to the occurrence of AMR in foodborne pathogens; yet few studies have been conducted to ascertain the magnitude of the problem and generate information that could address the AMR problem.

This study, therefore, aimed at characterizing the phenotypes of antimicrobial-resistant E. coli and Salmonella on raw retail broiler chicken carcasses in Zambia.

\section{Methods}

\subsection{Study Design}

A cross-sectional study was conducted between August 2017 and May 2018 in seven districts in Zambia that included Lusaka, Chilanga, Chongwe, Kafue, Choma, Kabwe and Kitwe (see Figure 1). Choma, Kabwe, Kitwe and Lusaka districts were purposely selected because as provincial headquarters, they are retail destinations for many poultry products from other districts, while Chilanga, Chongwe and Kafue districts were included due to their proximity to Lusaka, the capital city. The primary sampling units were the markets (broadly classified as Open markets and Supermarkets), and the secondary sampling units were the retail broiler chicken carcasses. An open market was defined as an unrestricted market, not housed in a building, where food products are often sold exposed, while a supermarket was defined as a restricted market, housed in a closed building with modernized facilities. $^{[18]}$

Copperbelt Province (Kitwe)
Central Province (Kabwe)
Lusaka Province (Lusaka,
Chilanga, Chongwe, Kafue)
Southern Province (Choma)

Figure 1. Map of Zambia showing the provinces and location of the districts that were sampled 
Proportion stratified random sampling was employed where Open markets and Supermarkets were the strata. At the time of the study, information collected from the respective City Councils revealed that there were 47 supermarkets and 33 open markets in Lusaka province, five open markets and four supermarkets in Choma, seven open markets and eight supermarkets in Kitwe, nine open markets and six supermarkets in Kabwe, three open markets and two supermarkets in Kafue, three open markets and one Supermarket in Chilanga, and one open market and no supermarket in Chongwe. This formed the sampling frame from which a study population was drawn.

\subsection{Sample size calculation}

The sample size for estimation of a single proportion was calculated using Epi tools software (www.epitools.ausvet.com) based on the following assumptions: prevalence of AMR E. coli on raw retail broiler chicken carcasses $=25 \%$; $^{[19]}$ confidence level $=95 \%$; level of precision $=5 \%$. Using the above assumptions, the minimum sample size calculated was 289 , and the distribution of sampling sites is as outlined in Table 1.

\subsection{Sampling from open markets}

From the open markets within the Lusaka district that were sampled $(n=22)$, two shops trading in broiler chicken carcasses at each market were selected, and from each shop, two broiler chicken carcasses purchased. Furthermore, at the market where open stands (display tables) instead of shops trading in dressed broiler chickens were available, one sample from each stand was collected. For other districts, considering the limited number of markets that traded in broiler chicken carcasses, all of them were included in the study, and at least two samples from each market were collected, bringing the total number of samples from open markets to 178 (see Table 1).

Table 1. Summary distribution of samples collected by market type and district

\begin{tabular}{|c|c|c|c|c|c|c|}
\hline District & $\begin{array}{l}\text { No. of open } \\
\text { markets }\end{array}$ & $\begin{array}{lr}\text { No. } & \text { of } \\
\text { Supermarkets }\end{array}$ & $\begin{array}{l}\text { Total No. of } \\
\text { markets }\end{array}$ & $\begin{array}{l}\text { Samples from } \\
\text { Open Markets }(\%)\end{array}$ & $\begin{array}{lr}\text { Samples } & \text { from } \\
\text { Supermarkets }(\%)\end{array}$ & $\begin{array}{l}\text { Total No. of } \\
\text { samples }(\%)\end{array}$ \\
\hline Chilanga & 2 & 1 & 3 & $8(4.5)$ & $4(2.6)$ & $12(3.6)$ \\
\hline Chongwe & 1 & 0 & 1 & $11(6.2)$ & $0(0.0)$ & $11(3.3)$ \\
\hline Kafue & 1 & 2 & 3 & $2(1.1)$ & $6(3.9)$ & $8(2.4)$ \\
\hline Lusaka & 22 & 34 & 56 & $113(63.5)$ & $106(68.8)$ & $219(66.0)$ \\
\hline Kitwe & 7 & 8 & 15 & $15(8.4)$ & $18(11.7)$ & $33(9.9)$ \\
\hline Choma & 4 & 2 & 6 & $14(7.9)$ & $7(4.5)$ & $21(6.3)$ \\
\hline Kabwe & 5 & 3 & 8 & $15(8.4)$ & $13(8.5)$ & $28(8.5)$ \\
\hline Total & 42 & 50 & 92 & $178(100.0)$ & $154(100.0)$ & 332 (100.0) \\
\hline
\end{tabular}

\subsection{Sampling from the Supermarket}

From each Supermarket in all districts, a maximum of four different brands of retail broiler chicken carcasses was sampled (one of each brand), though some sampling sites had less than the maximum number. Therefore, the number of broiler carcasses from supermarkets in this study was 154 (see Table 1).

Upon purchase, all samples were transported in a cooler box containing ice packs to the laboratory and processed within 8 hours.

\subsection{Laboratory Analysis}

Laboratory isolation included a whole carcass rinse in buffered peptone water (Oxoid), pre-enrichment of an aliquot of the rinsate and subsequent incubation at $37^{\circ} \mathrm{C}$ overnight. Processing of pre-enriched broths was undertaken in the Public Health Laboratory, School of Veterinary Medicine. The Carcass Rinse technique outlined by the USDA Food Safety and Inspection Service was used with a few modifications. ${ }^{[20]}$

Published by Sciedu Press
Whole chicken carcasses were aseptically placed in sterile 3 -litre ziplock bags. $450 \mathrm{~mL}$ of sterile buffered peptone water (Oxoid UK) was poured into each of the bags containing the carcasses. The open ends of the bags were then twisted to hold the bags closed, and the entire carcass was rinsed using a repeated rocking motion 30 times. The bags were then opened, and the carcasses removed. The rinsate was then collected in sterile containers by puncturing the "v"-end of the bags and used for further analysis.

The methods proposed by the Food and Drug Administration's Bacteriological Analytical Manual ${ }^{[21]}$ were used with a few modifications for the isolation of Salmonella and $E$. coli. During the carcass rinse technique, $450 \mathrm{~mL}$ of sterile buffered peptone water was also poured into an empty bag that did not contain a carcass to act as a control. The rinsate was incubated overnight and later streaked onto MacConkey agar plate (Oxoid, UK) to ensure that the batch of bags was sterile and that the organisms isolated were indeed from the chicken carcasses and not the bags used for rinsing. $10 \mu \mathrm{L}$ 
of the incubated broth was then transferred to MacConkey agar (Oxoid UK), and resulting colonies were gram stained for detection of Gram-negative short rods, which were subsequently sub-cultured onto Eosin Methylene Blue (EMB) agar (Oxoid UK). Colonies that showed a metallic green sheen were subjected to biochemical tests using Analytical Profile Index (API 20E) (Biomerieux ${ }^{\circledR}$ ) for identification for $E$. coli isolates. $1 \mathrm{ml}$ of the incubated pre-enrichment broth was also transferred to Rappaport Vassiliadis (Oxoid UK) and later subcultured on Xylose-Lysine Deoxycholate agar (Oxoid UK). Pink and black colonies on XLD agar were then Gramstained and subjected to biochemical tests for identification of Salmonella using API 20E. Further confirmation of the isolates was done using $16 \mathrm{~S}$ rRNA sequencing. ${ }^{[22]}$

The Kirby-Bauer disk diffusion technique for AST was used on all confirmed Salmonella and E. coli isolates using a panel of 9 different antibiotics. ${ }^{[23]}$ The isolates were prepared by sub-culturing onto Blood agar (Oxoid UK) overnight at $37^{\circ} \mathrm{C}$. One or two colonies were then suspended in $4 \mathrm{ml}$ of $0.9 \%$ sodium chloride solution and their turbidity compared to that of a 0.5 McFarland's turbidity standard. An inoculum of the suspension was then spread on two Müeller Hinton agar (4 ml thickness) plates (Oxoid UK) until the entire surfaces of the plates were covered. Five different antibiotic wafers from the nine chosen for the study were then placed on the surface of each of the two plates using the applicator (Oxoid). Two plates were used for each isolate to accommodate the nine antibiotics. The antibiotics that were used were amoxicillin-clavulanic acid $(30 \mu \mathrm{g})$, ampicillin $(10 \mu \mathrm{g})$, cefotaxime $(30 \mu \mathrm{g})$, chloramphenicol $(30 \mu \mathrm{g})$, ciprofloxacin $(5 \mu \mathrm{g})$, imipenem $(10 \mu \mathrm{g})$, nalidixic acid $(30 \mu \mathrm{g})$, tetracycline $(30 \mu \mathrm{g})$ and trimethoprim-sulfamethoxazole $(25 \mu \mathrm{g})$. The list of antibiotics was prioritized based on the most frequently used in the poultry industry in Zambia and also based on the priority list by the WHO and OIE of critical antibiotics. ${ }^{[24]}$ The plates were then incubated at $37^{\circ} \mathrm{C}$ for $24 \mathrm{hrs}$. The measured diameters of the zones of inhibition were entered into WHONET 2018, a laboratory software database that allows the management, analysis and storage of AST data. The trends and other descriptive statistics were then summarized in form of spreadsheets, tables and graphs. ${ }^{[25,26]}$ An isolate was considered to be completely resistant to an antimicrobial when it had no zone of inhibition around the antimicrobial disc after the incubation. ${ }^{[23]}$ The interpretation of AST results was based on the Clinical and laboratory standards institute (CLSI) guidelines 2018. ${ }^{[27]}$ Every batch of samples was processed along with a positive and negative control using E. coli 25922 (ATCC) and Salmonella typhimurium 14028 (ATCC).

\section{RESUltS}

\subsection{Descriptive statistics}

A total of 332 retail broiler chicken carcasses were sampled from both supermarkets (154) and open markets (178), from which 189 (56.9\%) and 05 (1.5\%) E. coli and Salmonella, respectively, were isolated and identified. The two pathogens of interest were mostly isolated from supermarkets (see Table 2).

Table 2. Distribution of isolates according to market types and district

\begin{tabular}{|c|c|c|c|c|c|c|}
\hline \multirow[t]{2}{*}{ District } & \multicolumn{3}{|c|}{ Open Market } & \multicolumn{3}{|c|}{ Supermarket } \\
\hline & $\begin{array}{l}\text { No. of } \\
\text { samples }\end{array}$ & $\begin{array}{l}\text { No. of } \\
\text { E. coli }(\%)\end{array}$ & $\begin{array}{l}\text { No. of } \\
\text { Salmonella }(\%)\end{array}$ & $\begin{array}{l}\text { No. of } \\
\text { samples }\end{array}$ & $\begin{array}{l}\text { No. of } \\
\text { E. coli }(\%)\end{array}$ & $\begin{array}{l}\text { No. of } \\
\text { Salmonella }(\%)\end{array}$ \\
\hline Chilanga & 8 & $0(0.0)$ & 0 & 4 & $4(100.0)$ & 0 \\
\hline Chongwe & 11 & $4(36.4)$ & 0 & 0 & 0 & 0 \\
\hline Kafue & 2 & $2(100.0)$ & 0 & 6 & $6(100.0)$ & 0 \\
\hline Lusaka & 113 & $73(64.6)$ & 1 & 106 & $59(55.7)$ & 4 \\
\hline Kitwe & 15 & $8(53.3)$ & 0 & 18 & $15(83.3)$ & 0 \\
\hline Choma & 14 & $7(50.0)$ & 0 & 7 & $5(71.4)$ & 0 \\
\hline Kabwe & 15 & $2(13.3)$ & 0 & 13 & $4(30.8)$ & 0 \\
\hline Total & 178 & $96(53.9)$ & $1(0.5)$ & 154 & $93(60.4)$ & $4(2.6)$ \\
\hline
\end{tabular}

\subsection{Antimicrobial susceptibility profiles}

E. coli isolates from retail broiler chicken carcasses obtained from open markets had a higher occurrence of resistance of $91.7 \%(n=88)$ to at least one antimicrobial agent in the AST testing, while those from supermarkets recorded $83.9 \%$ (n
=78). The overall resistance of $E$. coli isolates to at least one antimicrobial agent for both the open markets and supermarkets was $88 \%(n=166)$. However, $102 E$. coli and the 02 Salmonella isolates were completely resistant to at least one of the antimicrobials used. The E. coli isolates were 
resistant to tetracycline, trimethoprim-sulfamethoxazole and ampicillin with $79.4 \%(\mathrm{n}=150$ isolates $), 51.9 \%(\mathrm{n}=98$ isolates $)$ and $49.7 \%(n=94$ isolates $)$ resistance, respectively (see Table 3), while only ampicillin and tetracycline recorded resistance among the Salmonella isolates (see Table 4).

Table 3. Resistance profiles for $E$. coli isolates

\begin{tabular}{lllllll}
\hline Antimicrobial & $\begin{array}{l}\text { Breakpoints } \\
(\mathbf{m m})\end{array}$ & Number & \%R & \%I & \%S & \% R 95\% C.I. \\
\hline Ampicillin & $14-16$ & 189 & 51.9 & 4.8 & 43.4 & $44.5-59.2$ \\
Amoxicillin/Clavulanic acid & $14-17$ & 189 & 6.9 & 5.8 & 87.3 & $3.9-11.8$ \\
Cefotaxime & $23-25$ & 189 & 16.4 & 6.3 & 77.2 & $11.6-22.6$ \\
Imipenem & $20-22$ & 189 & 1.1 & 6.3 & 92.6 & $0.2-4.2$ \\
Nalidixic acid & $14-18$ & 189 & 24.3 & 9.5 & 66.1 & $18.5-31.2$ \\
Ciprofloxacin & $16-20$ & 189 & 10.1 & 4.2 & 85.7 & $6.4-15.5$ \\
Trimethoprim/Sulfamethoxazole & $11-15$ & 189 & 49.7 & 0.5 & 49.7 & $42.4-57.0$ \\
Chloramphenicol & $13-17$ & 189 & 16.4 & 4.8 & 78.8 & $11.6-22.6$ \\
Tetracycline & $12-14$ & 189 & 79.4 & 2.1 & 18.5 & $72.8-84.8$ \\
\hline
\end{tabular}

Table 4. Resistance profiles for Salmonella isolates

\begin{tabular}{lllllll}
\hline Antimicrobial & $\begin{array}{l}\text { Breakpoints } \\
(\mathbf{m m})\end{array}$ & Number & \% R & \%I & \%S & $\begin{array}{l}\text { \%R } \\
\text { 95\% C.I. }\end{array}$ \\
\hline Ampicillin & $14-16$ & 5 & 60 & 0 & 40 & $17.0-92.7$ \\
Amoxicillin/Clavulanic acid & $14-17$ & 5 & 0 & 20 & 80 & $0.0-53.7$ \\
Cefotaxime & $23-25$ & 5 & 0 & 20 & 80 & $0.0-53.7$ \\
Imipenem & $20-22$ & 5 & 0 & 0 & 100 & $0.0-53.7$ \\
Nalidixic acid & $14-18$ & 5 & 0 & 20 & 80 & $0.0-53.7$ \\
Ciprofloxacin & $21-30$ & 5 & 0 & 20 & 80 & $0.0-53.7$ \\
Trimethoprim/Sulfamethoxazole & $11-15$ & 5 & 0 & 0 & 100 & $0.0-53.7$ \\
Chloramphenicol & $13-17$ & 5 & 0 & 0 & 100 & $0.0-53.7$ \\
Tetracycline & $12-14$ & 5 & 40 & 20 & 40 & $7.3-83.0$ \\
\hline
\end{tabular}

None of the Salmonella isolates was Multidrug-resistant (MDR). MDR was defined as acquired nonsusceptibility to at least one agent in three or more antimicrobial categories; ${ }^{[28]}$ However, $36.5 \%(\mathrm{n}=69)$ of the $E$. coli isolates were MDR and 26 different patterns were observed (see Table 5).

The most common MDR patterns that were observed among the E. coli isolates were CHL-TCY-AMP-SXT (15.9\%), CTX -TCY-AMP-SXT (10.1\%), CIP-TCY-AMP-SXT (8.7\%).

\section{DiscuSsion}

This study isolated E. coli and Salmonella from retail broiler chicken carcasses traded in supermarkets and open markets in selected districts in Zambia. It further characterized the AMR phenotypes of E. coli and Salmonella isolates.

The recovery rate of E. coli and Salmonella sp was higher in Published by Sciedu Press samples from supermarkets $(60.4 \%$ and $2.6 \%$, respectively) as compared to those from open markets. These findings are different from those of a similar study conducted in Thailand, where authors reported a low recovery rate of $25 \%$ and $2 \%$ for E. coli and Salmonella, respectively. ${ }^{[19]}$ The disparity of findings could be attributed to a difference in processing methods and commercial production techniques that are highly automated in Thailand compared to the Zambian settings where the manual system is often used, hence exposing the carcasses to contamination. ${ }^{[29]}$

The overall contamination level of Salmonella sp in all samples was low (1.5\%). This was also observed in some studies done at the retail level. ${ }^{[30,31]}$ The low contamination rate could be attributed to the intermittent shading of Salmonella in poultry. ${ }^{[32]}$ 
Table 5. Antimicrobial Resistance Patterns for MDR isolates

\begin{tabular}{lll}
\hline Antimicrobial Resistance & $\begin{array}{l}\text { Number of isolates with } \\
\text { pattern }(\mathbf{n}, \boldsymbol{\%})\end{array}$ \\
\hline CTX-TCY-AMP & $2(2.9 \%)$ \\
CHL-TCY-SXT & $2(2.9 \%)$ \\
CHL-TCY-AMP & $3(4.3 \%)$ \\
CHL-CTX-TCY & $1(1.4 \%)$ \\
CHL-CIP-TCY & $1(1.4 \%)$ \\
TCY-AMP-SXT & $2(2.9 \%)$ \\
IPM-TCY-AMP-SXT & $1(1.4 \%)$ \\
CTX-TCY-AMP-SXT & $7(10.1 \%)$ \\
CTX-IPM-TCY-SXT & $4(5.8 \%)$ \\
CIP-TCY-AMP-SXT & $6(8.7 \%)$ \\
CIP-IPM-AMP-SXT & $1(1.4 \%)$ \\
CIP-CTX-TCY-SXT & $2(2.9 \%)$ \\
CIP-CTX-TCY & $1(1.4 \%)$ \\
CHL-TCY-AMP-SXT & $11(15.9 \%)$ \\
CHL-CTX-AMP-SXT & $1(1.4 \%)$ \\
CHL-CTX-TCY-SXT & $1(1.4 \%)$ \\
CHL-CIP-TCY-SXT & $3(4.3 \%)$ \\
CTX-TCY-AMP-SXT & $1(1.4 \%)$ \\
CIP-IPM-TCY-AMP-SXT & $1(1.4 \%)$ \\
CHL-IPM-TCY-AMP & $2(2.9 \%)$ \\
CHL-CTX-TCY-AMP-SXT & $4(5.8 \%)$ \\
CHL-CIP-TCY-AMP-SXT & $5(7.2 \%)$ \\
CHL-CIP-IPM-TCY-AMP-S & $1(1.4 \%)$ \\
XT & \\
CHL-CIP-CTX-TCY-AMP-S & $4(5.8 \%)$ \\
XT & \\
IPM-TCY-SXT & $1(1.4 \%)$ \\
CTX-TCY-SXT & $1(1.4 \%)$ \\
Total MDR & $\mathbf{6 9}(\mathbf{9 9 . 2 \% )}$ \\
\hline
\end{tabular}

E. coli and Salmonella sp. isolated from this study showed a high level of antibiotic resistance, including resistance to multiple antibiotics. E. coli isolates were resistant to tetracycline (79.4\%), ampicillin (51.9\%) and trimethoprim/sulfamethoxazole (49.7\%). This has also been observed in other parts of the world ${ }^{[33]}$ and could be attributed to the use of these antibiotics as growth promotors and for prevention of infection rather than for therapeutic purposes only. ${ }^{[34]}$ Salmonella isolates were resistant to ampicillin $(60.0 \%)$ and tetracycline $(40.0 \%)$. Similar resistance profiles for Salmonella isolated from food animals were reported by Johnson et al. in Canada's study. ${ }^{[35]}$

The high resistance to tetracyclines, sulfonamides and betalactam antibiotics could be attributed to the misuse of antibiotics in livestock and humans, especially among small poultry producers. A study that was conducted in five African countries, including Zambia, revealed that broiler producers relied on the poultry farm workers' experience and knowledge to make decisions regarding antimicrobial use. Further, the antimicrobials were sourced from local, private owned agro-veterinary drug shops, often without the involvement of animal health professionals. ${ }^{[36]}$ Due to this poor regulation of veterinary drugs and antibiotics, farmers could purchase antibiotics over the counter without a prescription ${ }^{[37-39]}$ Furthermore, the poor hygienic processing methods employed by small and medium-scale producers may facilitate the contamination of the carcasses with AMR organisms. The handling of the carcasses during slaughter, rinsing, transportation and sale may also introduce resistant organisms from humans and the environment into the carcasses. Retail broiler chicken carcasses that originate from commercial abattoirs may get contaminated mainly from the abattoir bench surfaces and intestines of the broilers during processing. ${ }^{[40]}$

Multidrug resistance was also reported among 69 (36.5\%) of the $189 \mathrm{E}$. coli isolates in this study. These findings are similar to other studies on AMR in both poultry and humans. ${ }^{[14,41]}$ The high resistance in poultry, especially, can be attributed to the use of antibiotics for preventive purposes by small-scale poultry farmers between weeks 4 and 6 of production to prevent high mortality rates due to colibacillosis in broilers. ${ }^{[42]}$ It has also been documented that tetracycline and sulfadimidine are commonly used antimicrobials for therapy, especially at small-scale production. ${ }^{[17,39]}$ Further, farmers tend to self-prescribe these drugs whenever they have a disease situation when raising the birds. ${ }^{[43,44]}$ Such misuse of antibiotics in livestock production has been reported to cause AMR. ${ }^{[45-49]}$

The results of this study have demonstrated the presence of antimicrobial resistant pathogens from both open markets and supermarkets in some of the most populated provincial industrial capitals of Zambia. This raises public health concerns because studies have shown that food producing animals, such as broilers, could be a major contributor to the antimicrobial resistance gene pool. ${ }^{[50,51]}$ These resistance genes could negatively affect the response of humans to antimicrobial therapy specifically among the immunocompromised populations, such as children under the age of five, the elderly and those suffering from chronic diseases. ${ }^{[52-54]}$

\section{Conclusion}

This study has demonstrated the presence of AMR E. coli and Salmonella on retail broiler chicken carcasses in selected districts in Zambia. It has also shown the presence of MDR and ESBL producing $E$. coli that are of public health concern if acquired by humans. The E. coli and Salmonella isolates were most resistant to tetracyclines, beta-lactams, 
sulfonamide and fluoroquinolone antibiotics. This could be attributed to the misuse of antibiotics at both commercial and small-scale levels of production. There is a need to regulate the use of antibiotics during broiler chicken production. It is also important for Zambia, and other developing countries, to set up a surveillance system that will monitor the procurement and use of antimicrobials in food-producing animals. This can be achieved using a one-health approach by incorporating all stakeholders involved in the broiler chicken production value-chain as well as those involved in animal and human health decision making to raise awareness on the AMR threat and its impact on public health.

\section{ACKNOWLEDGements}

We would like to thank Mr Joseph Ndebe; Mr Penjaninge Kapila; Mr Patrick Katemangwe; Mrs Lweendo HachambaSachikolo and Miss. Yambilani Nyirenda for the help rendered during sample processing. We would also like to thank the WHO-funded Advisory Group for Integrated Surveil- lance of Antimicrobial Resistance (AGISAR) Project at the University of Zambia and the World Bank-funded African Centre of Excellence in Infectious Diseases of Humans and Animals (ACEIDHA) programme for the provision of funds and research materials required for laboratory sample analysis and The Capacity Building in Zoonotic Disease Management Using Integrated Ecosystems Health Approach at the Human-Livestock-Wildlife Interface in the Eastern and Southern Africa (CAPAZOMANINTECO), under the NOHERD project, for sponsoring part of the research work. Our sincere gratitude also goes out to the technical staff at the Department of Disease Control and Department of Paraclinical Studies at the University of Zambia, School of veterinary medicine, for their technical support and guidance they rendered to us during my study.

\section{CONFlicts of InTEREST Disclosure}

The authors declare that they have no competing interests.

\section{REFERENCES}

[1] Musaba EC, Mseteka M. Cost efficiency of small-scale commercial broiler production in Zambia: A stochastic cost frontier approach, Developing Country Studies. 2014.

[2] Ahuja V, Sen A. Scope and Space for small scale poultry production in developing countries. Indian Institute of Management Ahmedabad. 2007; 12(2): 1-20 https://doi.org/10.1080/00045608. 2011. 652888

[3] Apata DF. Antibiotic resistance in poultry. International Journal of Poultry Science. 2009; 8(4): 404-408. https://doi.org/10.392 3/ijps. 2009.404.408

[4] WHO Global Report (2014) Antimicrobial resistance.

[5] Willem van S. The human gut resistome. Philosophical Transactions of the Royal Society B: Biological Sciences. 2015; 370(1670): 1-9. PMid:25918444. https://doi.org/10.1098/rstb.2014.0087

[6] Yassin AK, Gong J, Kelly P, et al. (2017)'Antimicrobial resistance in clinical Escherichia coli isolates from poultry and livestock, China. PLoS ONE. 2017; 12(9):e0185326. PMid:28934348. https://doi.org/10.1371/journal . pone. 0185326

[7] Centers for Disease Control and Prevention. Antibiotic / Antimicrobial Resistance (AR / AMR), CDC. 2018.

[8] Diarrassouba F, Diarra MS, Bach S, et al. Antibiotic Resistance and Virulence Genes in Commensal Escherichia coli and Salmonella Isolates from Commercial Broiler Chicken Farms. Journal of Food Protection. 2007 Jun; 70(6): 1316-27. PMid:17612058. https: //doi.org/10.4315/0362-028X-70.6.1316

[9] Foodborne Germs and Illnesses. Food Safety. CDC. 2016.

[10] World Health Organization (WHO). Fact Sheets on Food safety. Who. 2015.

[11] Gordon MA. Salmonella infections in immunocompromised adults. Journal of Infection. 2008; 56(6): 413-422. PMid:18474400. https : //doi.org/10.1016/j.jinf.2008.03.012

[12] Clarke KR, Kanyanga MK, Musenga E, et al. Outbreak of multidrug resistant salmonella Typhi, Lusaka, zambia 2011-2012. American
Journal of Tropical Medicine and Hygiene. Conference: 61st Annual Meeting of the American Society of Tropical Medicine and Hygiene, ASTMH. 2012.

[13] Mshana SE, Matee M, Rweyemamu M. Antimicrobial resistance in human and animal pathogens in Zambia, Democratic Republic of Congo, Mozambique and Tanzania: An urgent need of a sustainable surveillance system. Annals of Clinical Microbiology and Antimicrobials. 2013 Oct 12; 12: 28. PMid:24119299. https://doi.org/10.1186/1476-0711-12-28

[14] Chiyangi H, Muma JB, Malama S, et al. Identification and antimicrobial resistance patterns of bacterial enteropathogens from children aged 0-59 months at the University Teaching Hospital, Lusaka, Zambia: A prospective cross-sectional study. BMC Infectious Diseases. 2017; 17: 117. PMid:28152988. https ://doi.org/10.1186/s1 2879-017-2232-0

[15] Byarugaba DK. Antimicrobial resistance in developing countries and responsible risk factors. International Journal of Antimicrobial Agents. 2004; 24(2): 105-110. PMid:15288307. https://doi.or g/10.1016/j.ijantimicag. 2004.02.015

[16] Thapar N, Sanderson IR. Diarrhoea in children: An interface between developing and developed countries. Lancet. 2004; 363(9409): 641653. https://doi.org/10.1016/S0140-6736(04) 15599-2

[17] Mainda G, Bessell PR, Muma JB, et al. (2015) 'Prevalence and patterns of antimicrobial resistance among Escherichia coli isolated from Zambian dairy cattle across different production systems. Scientific Reports. 2015; 5: 12439. PMid:26211388. https: //doi.org/10.1038/srep12439

[18] Bumbangi NF, Muma JB, Choongo K, et al. Occurrence and factors associated with aflatoxin contamination of raw peanuts from Lusaka district's markets, Zambia. Food Control. 2016; 68: 291-296. https://doi.org/10.1016/j.foodcont. 2016.04.004

[19] Vindigni SM, Srijan A, Wongstitwilairoong B, et al. Prevalence of foodborne microorganisms in retail foods in Thailand', Food- 
borne Pathogens and Disease. 2007; 4(2): 208-15. PMid:17600488. https://doi.org/10.1089/fpd.2006.0077

[20] D'Aoust JY, Stotland P, Boville A. Sampling methods for detection of Salmonella in raw chicken carcasses. J Food Sci. 1982; 47:1643-1644. https://doi.org/10.1111/j.1365-2621.1982.tb05002.x

[21] US Food and Drug Administration (FDA) Microbiological Methods \& Bacteriological Analytical Manual (BAM). US. Department of Health and Human Services.

[22] Weisburg WG, Barns SM, Pelletier DA, et al. (1991) 16S ribosomal DNA amplification for phylogenetic study', Journal of Bacteriology. 1991 Jan; 173(2): 697-703. PMid:1987160. https://doi.org/10 $.1128 / J B .173 .2 .697-703.1991$

[23] Kirby-bauer T. Kirby-Bauer Test for Antibiotic Susceptibility. 1961

[24] Oie. OIE List of Antimicrobials of Veterinary Importance. World Organization for Animal Health. 2007.

[25] Agarwal A, Kapila K. Kumar S. WHONET software for the surveillance of antimicrobial susceptibility. Medical Journal Armed Forces India. 2009; 65(3): 264-266. https ://doi.org/10.1016/S037 7-1237 (09) 80020-8

[26] Ghosh AN, Bhatta DR, Ansari MT, et al. Application of WHONET in the antimicrobial resistance surveillance of uropathogens: A first user experience from Nepal. Journal of Clinical and Diagnostic Research. 2013; 7(5): 845-8. PMid:23814725. https://doi.org/10.7860/ JCDR/2013/5193. 2955

[27] Replaces M, Melvin P, Weinstein MD, et al. CLSI M100-ED28: 2018 Performance Standards for Antimicrobial Susceptibility Testing, 28th Edition. 2018.

[28] Basak S, Singh P, Rajurkar M. Multidrug Resistant and Extensively Drug Resistant Bacteria: A Study. Journal of Pathogens. 2016; 2016 : 4065603. PMid:26942013. https ://doi .org/10.1155/2016/4 065603

[29] Phiri N, Mainda G, Mukuma M, et al. Antibiotic-resistant Salmonella species and Escherichia coli in broiler chickens from farms, abattoirs, and open markets in selected districts of Zambia. Journal of Epidemiological Research. 2020; 6(1): 13. https://doi.org/10.5430/ jer.v6n1p13

[30] Cosby DE, Cox NA, Harrison MA, et al. Salmonella and antimicrobial resistance in broilers: A review. Journal of Applied Poultry Research. 2015; 24(3): 408-426. https://doi.org/10.3382/ja $\mathrm{pr} / \mathrm{pfv038}$

[31] [Mpundu P, Mbewe AR, Muma JB, et al. Evaluation of bacterial contamination in dressed chickens in lusaka abattoirs. Frontiers in Public Health. 2019 Feb 19; 7: 19. PMid:30838192. https: //doi.org/10.3389/fpubh.2019.00019

[32] Van IF, Buck DJ, Pasmans F, et al. Intermittent long-term shedding and induction of carrier birds after infection of chickens early posthatch with a low or high dose of Salmonella enteritidis. Poultry Science. 2004; 83(11): 1911-1916. PMid:15554070. https : //doi.org/10.1093/ps/83.11.1911

[33] Talebiyan R, Kheradmand M, Khamesipour F, et al. Multiple antimicrobial resistance of escherichia coli isolated from chickens in Iran. Veterinary Medicine International. 2014; 2014: 491418. PMid:25548716. https ://doi.org/10.1155/2014/491418

[34] Agyare C, Boamah VE, Zumbi CN, et al. Antibiotic Use in Poultry Production and Its Effects on Bacterial Resistance in Antimicrobial Resistance - A Global Threat. 2018. https ://doi.org/10.5772/ intechopen.79371

[35] Johnson JM, Rajic A, McMullen LM. Antimicrobial resistance of selected Salmonella isolates from food animals and food in Alberta. Canadian Veterinary Journal. 2005 Feb; 46(2): 141-146.

[36] Caudell MA, Dorado G, Ecford S, et al. Towards a bottom-up understanding of antimicrobial use and resistance on the farm: A knowl- edge, attitudes, and practices survey across livestock systems in five African countries. PLoS ONE. 2020 Jan 24; 15(1): e0220274. PMid:31978098. https://doi.org/10.1371/journal.pone.0 220274

[37] Mainda G. Molecular epidemiology of antimicrobial resistance (amr) and shiga toxin producing e coli (stec) in dairy herds of central Zambia, PQDT - UK. \& Ireland. 2016.

[38] Manyi-Loh C, Mamphweli S, Meyer E, et al. Antibiotic use in agriculture and its consequential resistance in environmental sources: Potential public health implications. Molecules. 2018 Mar 30;23(4):795 PMid:29601469. https ://doi .org/10.3390/molecules 23040 795

[39] Kimera ZI, Mshana SE, Rweyemamu M, et al. Antimicrobial use and resistance in food-producing animals and the environment: An African perspective', Antimicrobial Resistance and Infection Control 2020; 9(1): 12. PMid:32122406. https://doi.org/10.1186/s1 3756-020-0697-x

[40] Voidarou C, Vassos D, Razos G, et al. Microbial challenges of poultry meat production. Anaerobe. 2011 Dec; 17(6): 341-3. PMid:21718794 https : //doi.org/10.1016/j . anaerobe. 2011.05.018

[41] van den Bogaard AE, London N, Driessen C, Antibiotic resistance of faecal Escherichia coli in poultry, poultry farmers and poultry slaughterers', Journal of Antimicrobial Chemotherapy. 2001 July; 47(6):763-71. PMid:11389108. https ://doi.org/10.1093/ja c/47.6.763

[42] Nolan LK, Barnes JH, Vaillancourt J, et al. Colibacillosis. Diseases of Poultry: Thirteenth Edition. https ://doi .org/10.1002/9781 $119421481 . \operatorname{ch} 18$

[43] Guetiya RE, Zambou NF, Anyangwe FF, et al.Abusive use of antibiotics in poultry farming in Cameroon and the public health implications. British Poultry Science. 2016 Aug; 57(4): 483-93. PMid:27113432. https://doi.org/10.1080/00071668.2016. 1180668

[44] Xu J, Sangthong R, McNeil E, et al. (2020) Antibiotic use in chicken farms in northwestern China. Antimicrobial Resistance and Infection Control. 2020; 9(1): 9. PMid:31921416. https ://doi.org/10.1 $186 / \mathrm{s} 13756-019-0672-6$

[45] John AL. Mechanisms of Antibiotic Resistance. Annual Reports in Medicinal Chemistry. 1982; 17: 119-127. https ://doi.org/10.1 016/S0065-7743(08)60495-9

[46] Ngoma M, Suzuki A, Sato T, et al. Antibiotic resistance of Escherichia coli and Salmonella from apparently healthy slaughtered cattle and pigs, and diseased animals in Zambia. Japanese Journal of Veterinary Research. 1993 Apr; 41(1): 1-10.

[47] Koluman A, Dikici A. Antimicrobial resistance of emerging foodborne pathogens: Status quo and global trends. Critical Reviews in Microbiology. 2013 Feb;39(1):57-69. PMid:22639875. https : //doi.org/10.3109/1040841X.2012.691458

[48] Kalonda A, Kwenda G, Lukwesa-Musyani C, et al. Characterization of Antimicrobial Resistance in Salmonella enterica Serovars Typhi and Paratyphi B in Zambia. Jour of Med Sc \& Tech. 2015.

[49] Ayukekbong JA, Ntemgwa M, Atabe AN. 'The threat of antimicrobial resistance in developing countries: Causes and control strategies. Antimicrobial Resistance and Infection Control. 2017 May 15; 6: 47. PMid:28515903. https://doi.org/10.1186/s13756-0 $17-0208-\mathrm{x}$

[50] Nobrega DB, Tang KL, Caffrey NP, et al. Prevalence of antimicrobial resistance genes and its association with restricted antimicrobial use in food-producing animals: a systematic review and meta-analysis. The Journal of Antimicrobial Chemotherapy. 2021. PMid:33146719. https://doi.org/10.1093/jac/dkaa443 
[51] Yang K, Wang A, Fu M, et al. (2020) Investigation of incidents and trends of antimicrobial resistance in foodborne pathogens in eight countries from historical sample data. International Journal of Environmental Research and Public Health. 2020; 17(2): 472. PMid:31936874. https://doi.org/10.3390/ijerph17020472

[52] Denegre AA, Mbah ML, Myers K, et al. Emergence of antibiotic resistance in immunocompromised host populations: A case study of emerging antibiotic resistant tuberculosis in AIDS patients. PLoS ONE. 2019; 14(2): e0212969. PMid:30817798. https : //doi.org/10.1371/journal.pone.0212969
[53] Alagna L, Palomba E, Mangioni D, et al. Multidrug-resistant gramnegative bacteria decolonization in immunocompromised patients: A focus on fecal microbiota transplantation. International Journal of Molecular Sciences. 2020; 21(16): 5619. PMid:32764526. https://doi.org/10.3390/ijms21165619

[54] Wolf J, Gerber JS, Smith MJ. Antimicrobial stewardship in immunocompromised hosts. Pediatric Transplant and Oncology Infectious Diseases. 2021. https://doi.org/10.1016/B978-0-323-641 98-2.00020-8 